\title{
Relationship between Acidity and Activity on Propane Conversion over Metal-Modified HZSM-5 Catalysts
}

\author{
Hao Zhou ${ }^{1}$, Fucan Zhang ${ }^{1,2}{ }^{(\mathbb{C}}$, Keming $\mathrm{Ji}^{1, *}$, Junhua Gao ${ }^{1, *}$, Ping Liu ${ }^{1, *}$, Kan Zhang ${ }^{1, *}$ and Se Wu ${ }^{3}$ \\ 1 State Key Laboratory of Coal Conversion, Institute of Coal Chemistry, Chinese Academy of Sciences, \\ Taiyuan 030001, China; zhouhao@sxicc.ac.cn (H.Z.); 2019215276@student.cup.edu.cn (F.Z.) \\ 2 State Key Laboratory of Heavy Oil Processing, China University of Petroleum, Beijing 102249, China \\ 3 State Grid Shanxi Electric Power Company, Taiyuan 030021, China; sir1983@163.com \\ * Correspondence: jikeming@sxicc.ac.cn (K.J.); gaojunhua@sxicc.ac.cn (J.G.); pingliu@sxicc.ac.cn (P.L.); \\ zhangkan@sxicc.ac.cn (K.Z.)
}

Citation: Zhou, H.; Zhang, F.; Ji, K.; Gao, J.; Liu, P.; Zhang, K.; Wu, S. Relationship between Acidity and Activity on Propane Conversion over Metal-Modified HZSM-5 Catalysts. Catalysts 2021, 11, 1138. https:// doi.org/10.3390/catal11101138

Academic Editors: Kyungsu Na and Narendra Kumar

Received: 4 June 2021

Accepted: 15 September 2021

Published: 23 September 2021

Publisher's Note: MDPI stays neutral with regard to jurisdictional claims in published maps and institutional affiliations.

Copyright: () 2021 by the authors. Licensee MDPI, Basel, Switzerland. This article is an open access article distributed under the terms and conditions of the Creative Commons Attribution (CC BY) license (https:// creativecommons.org/licenses/by/ $4.0 /)$.

\begin{abstract}
A systematic study of the comparative performances of different metal-impregnated HZSM5 catalysts $(\mathrm{Zn}, \mathrm{Ga}, \mathrm{Mo}, \mathrm{Co}$, and $\mathrm{Zr}$ ) for propane conversion is presented. The physicochemical properties of catalysts were characterized by means of XRD, BET, SEM, TEM, FTIR, XPS, ${ }^{27}$ Al MAS $\mathrm{NMR}, \mathrm{NH}_{3}$-TPD and Py-FTIR. It was found that the acidities of the catalysts were significantly influenced by loading metal. More specifically, Mo-, Co- or Zr-modified catalysts showed a large metal size and low acidic density, resulting high olefin selectivity, while $\mathrm{Zn}$ - or Ga-modified catalysts maintained their small metal size and acidic density, and mainly reduced B/L due to the Lewis acid sites created by $\mathrm{Zn}$ or Ga species, resulting in high aromatics selectivity. Experimental results also showed that there is a balance between metals size and medium and strong acidity on propane conversion. Moreover, based on the different acidity of metal-modified HZSM-5 catalysts, the mechanism of propane conversion was also discussed.
\end{abstract}

Keywords: metal modification; HZSM-5; acidity; selectivity; propane conversion

\section{Introduction}

The increasing energy demand and reducing fossil fuel resources make it imperative to develop new processes for the production of transportation fuels and chemicals. Catalytic conversion of light alkanes to more valuable chemicals, commodities, and fuels has attracted much attention in recent years [1-3]. Giving the scarcity of fossil fuels and suddenly increased low-cost light alkanes supplement from the shale gas revolution, propane conversion is becoming popular, and is regarded as an attractive way to meet the increasing demand for propylene and aromatics [4-6].

Propane dehydrogenation (PDH) processes was commercially applied by the Catofin process from CB\&I Lummus (Chicago, USA) and the Oleflex process from UOP (New Jersey, USA). Due to their outstanding propylene selectivity and catalyst stability, $\mathrm{Al}_{2} \mathrm{O}_{3}$ supported PtSn (Oleflex process from UOP) and $\mathrm{CrO}_{x}$ (Catofin process from CB\&I Lummus) catalysts have been widely used in industrial $\mathrm{PDH}$ processes [7]. Despite high initial propylene yields, both processes inevitably undergo rapid catalyst deactivation and decreased propylene selectivity. Moreover, $\mathrm{Pt}$ is rather costly and $\mathrm{Cr}$ is environmentally unfriendly. Hence, the exploration of effective and stable catalysts is of great significance for industrial application.

Zeolites with ordered microporous structures and outstanding thermal stability are regarded as ideal supports materials. Sun, Q. and co-workers [8] demonstrated that the PtZn@zeolite catalysts shown the best performances for PDH conversion, which are superior to the state-of-the-art supported Pt-based catalysts. However, introducing $\mathrm{Al}$ into zeolites has a negative effect on the selectivity of propylene due to the resultant undesirable Brønsted acidity [9]. Nevertheless, propane feed stocks can be also converted 
to aromatics on strong-acidity zeolite through propane aromatization processes. In this process, a reaction mechanism is proposed whereby metal active sites activate reactants to produce ethylene and propylene as intermediates, and then oligomerization, cyclization of the intermediates to produce aromatics on acid sites of zeolite. According to the propane conversion reaction mechanism, the synergetic effect between metal active sites and the acid properties of zeolite is key factor in determining catalytic performance.

The accessibility, strength, distribution, and nature of zeolite acid sites play a crucial role in many catalytic reactions [10-12]. Especially for HZSM-5 with a low Si/Al ratio, the aromatization could more likely occur on its strong acid sites and the aromatics could be produced with high selectivity [13]. While increasing the Si / Al ratio of HZSM-5 could reduce the density of acid sites, so that the selectivity of light alkenes was increased $[14,15]$. Long F. Lin et al. [11] also concluded that, for the catalytic cracking of 1-pentene to propylene, the main reaction pathways and the molar ratio of propylene to ethene were controlled by acid strength. Moreover, the nature (type) of acid sites is also crucial factor in determining product selectivity. Yarulina et al. [16] demonstrated that Brønsted acid sites is key to the selective formation of propylene from methanol, but a large number of Lewis acid sites is favorable to increase the selectivity of aromatics [17].

Various metal oxides supported zeolite have been widely investigated for light alkane (i.e., methane, ethane, propane) conversion, including precious metal $\mathrm{Pt}[18,19]$ and transition metal Zn [20-25], Ga [26-30], Mo [31,32], Co [33], Zr [34-36] oxides, etc. Moreover, metal modification also has a potential effect on the acidity of ZSM-5. Chen et al. [9] found that Lewis acid sites could created by Zn species. Xiao et al. [26] also concluded that the super catalytic behavior was attributed to the synergistic effect between the strong Lewis acid sites generated by the $(\mathrm{GaO})^{+}$species and the Brønsted acid sites. However, in comparison with Zn- or Ga-modified ZSM-5, Mo/H-ZSM-5 showed lower acidity and higher cracking activity with high selectivity toward methane, ethene, and ethane [37,38]. Though numerous works have studied propane conversion over various metals promoted ZSM-5 catalysts, there is no clear picture of the comparative performances of these catalysts. In this respect, a study dealing with the acidity of metal-loaded ZSM- 5 on the catalytic performance would be valuable.

In this work, a series of metal (i.e., Zn, Ga, Mo, Co, and Zr) modified HZSM-5 catalysts were prepared by impregnation and used for propane conversion. The influence of acidity of metal-modified HZSM- 5 on activity and selectivity in propane conversion was investigated thoroughly. Moreover, based on the different acidity of metal-modified HZSM5 catalysts and detailed products distribution, the mechanism of propane conversion on metal-modified zeolite catalysts was also discussed. It is anticipated that the results presented here complement those of parallel contributors and provide guidance for the rational selection of highly active catalysts for propane conversion.

\section{Results}

\subsection{Texture Properties of the Catalysts}

The powder XRD patterns of the reduced samples are presented in Figure 1. All samples exhibited typical ZSM-5 zeolite structure without the appearance of any other peak, suggesting that metal dispersion was uniform on zeolite and metallic modification did not affect the framework structure. However, the peak intensity was quite different for the modified zeolites. The as-synthesized HZSM- 5 has the highest crystallinity and is also selected as a reference sample ( $100 \%$ Crystallinity). It can be seen that the peak intensity of all the modified catalysts decreased (as shown in Table 1). This indicates that the metal modification leads to decrease in structure orderliness. 


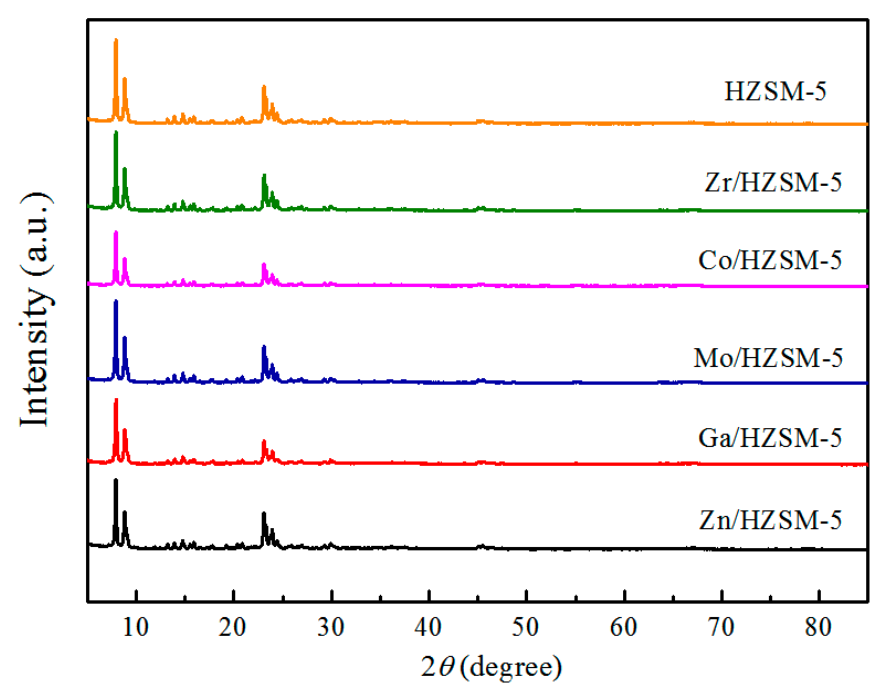

Figure 1. X-ray diffraction patterns of the catalysts with hydrogen pre-treatment at $873 \mathrm{~K}$ for $2 \mathrm{~h}$.

Table 1. Texture properties of the catalysts ${ }^{a}$.

\begin{tabular}{|c|c|c|c|c|c|c|}
\hline Catalyst & $\begin{array}{c}\text { Relative } \\
\text { Crystallinity }{ }^{\mathrm{b}}(\%)\end{array}$ & $\begin{array}{c}\text { Metal Content }{ }^{c} \\
(w t \%)\end{array}$ & $S_{\text {BET }}{ }^{d}\left(m^{2} g^{-1}\right)$ & $S_{\text {Micro }}{ }^{e}\left(m^{2} g^{-1}\right)$ & $\mathrm{V}_{\text {Total }}{ }^{\mathrm{d}}\left(\mathrm{cm}^{3} \mathrm{~g}^{-1}\right)$ & $V_{\text {Micro }}{ }^{e}\left(\mathrm{~cm}^{3} \mathrm{~g}^{-1}\right)$ \\
\hline Zn/HZSM-5 & 73.7 & 1.98 & 326.2 & 268.4 & 0.437 & 0.133 \\
\hline Ga/HZSM-5 & 93.5 & 1.99 & 325.8 & 268.2 & 0.435 & 0.132 \\
\hline Mo/HZSM-5 & 87.9 & 1.95 & 328.7 & 270.8 & 0.431 & 0.129 \\
\hline Co/HZSM-5 & 62.3 & 1.97 & 326.1 & 268.4 & 0.436 & 0.132 \\
\hline $\mathrm{Zr} / \mathrm{HZSM}-5$ & 89.8 & 1.98 & 327.5 & 269.5 & 0.438 & 0.133 \\
\hline HZSM-5 & 100.0 & - & 343.1 & 284.7 & 0.453 & 0.147 \\
\hline
\end{tabular}

${ }^{a}$ The catalysts was pre-treated with hydrogen at $873 \mathrm{~K}$ for $2 \mathrm{~h} .{ }^{\mathrm{b}}$ The relative crystallinity calculated by XRD. ${ }^{\mathrm{c}}$ The mass metal loading content determined by ICP-AES. ${ }^{\mathrm{d}}$ Determined by applying the multi-point BET. ${ }^{\mathrm{e}}$ Determined by applying the $t$-plot method.

The SEM images in Figure 2a show that the HZSM-5 exhibited a clear boundary and severely agglomerated morphology with rough surface. The nano-sized crystal of HZSM-5 zeolite was irregular with a spherical or elliptical shape. The HZSM-5 sample comprised of large quantities of small crystallites with the average crystal size of approximately $115 \mathrm{~nm}$ (Figure S1). The morphology of catalysts has no obvious changes after metal modification. As shown in Figure S1, the crystal size of all the samples had a wide distribution (about $40-220 \mathrm{~nm}$ ) with the average crystal size about $114.9-118.6 \mathrm{~nm}$, and the crystals larger than $160 \mathrm{~nm}$ or smaller than $80 \mathrm{~nm}$ existed but there were very few. Figure 3 exhibited a partial view of the ZSM- 5 crystal and metal-loaded ZSM- 5 crystal. The lattice fringes of HZSM-5 zeolites was confirmed in the TEM images, suggesting the zeolite structure was not changed after the metal was modified. The size of loaded metal nanoparticles was also measured by TEM. Uniform distribution of loaded metal species could observed, while some Co nanoparticles were also observed forming aggregates (Figure 3c). Indeed, as shown in Figure S2, the average size of Co species was $8.3 \mathrm{~nm}$, which was much larger than $\mathrm{Zr}(6.8 \mathrm{~nm}), \mathrm{Mo}(7.2 \mathrm{~nm}), \mathrm{Ga}(6.2 \mathrm{~nm})$ or $\mathrm{Zn}(4.7 \mathrm{~nm})$. These facts indicate that the morphology and structure was not changed after metal modification and there was a good dispersion of metal over modified HZSM-5 catalyst, which is in agreement with the $\mathrm{XRD}$ results. 

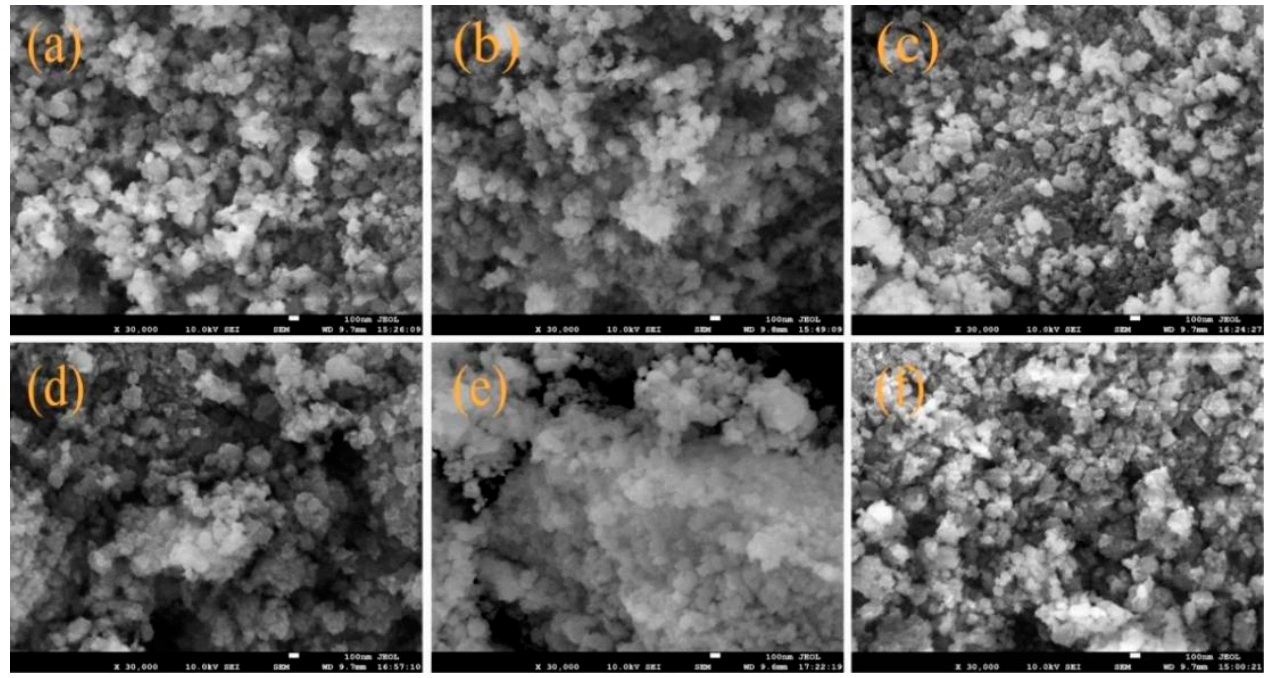

Figure 2. Scanning electron microscopy images of the catalysts with hydrogen pre-treatment. (a): HZSM-5; (b): Zr/HZSM-5; (c): Co/HZSM-5; (d): Mo/HZSM-5; (e): Ga/HZSM-5: (f): Zn/HZSM-5.
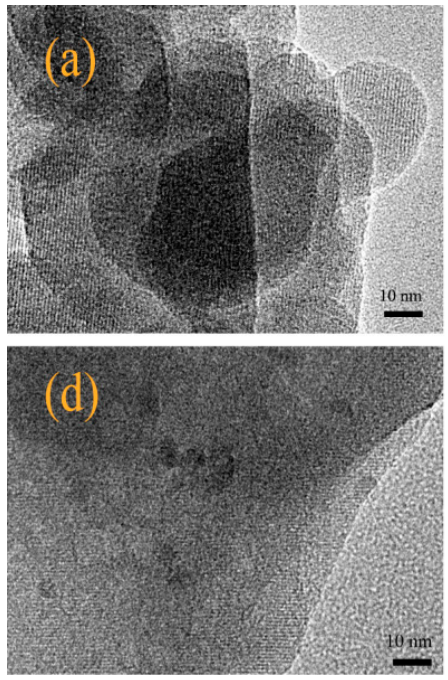
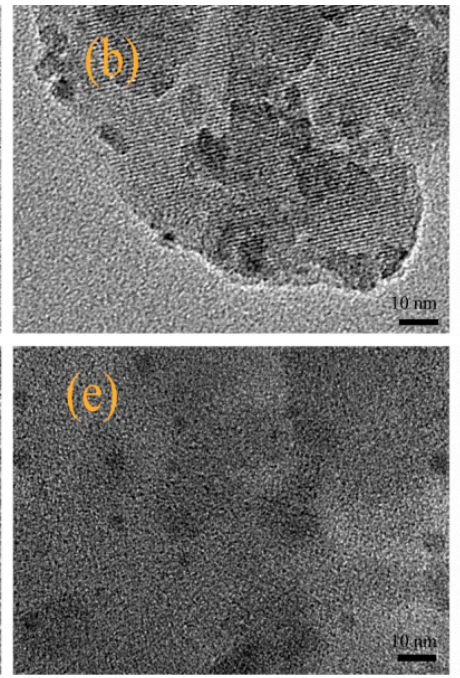
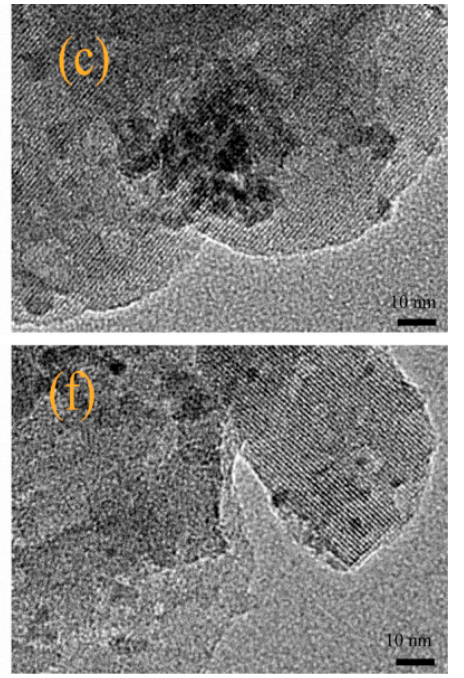

Figure 3. Transmission electron microscopy images of the catalysts with hydrogen pre-treatment. (a): HZSM-5; (b): Zr/HZSM-5; (c): Co/HZSM-5; (d): Mo/HZSM-5; (e): Ga/HZSM-5; (f): Zn/HZSM-5.

The structural and textural properties of the reduced samples were characterized with $\mathrm{N}_{2}$ adsorption-desorption. As listed in Table 1, the micropore surface area, micropore volume, external surface and mesoporous volume of the metal-modified catalysts were slightly decreased. This suggested that metallic species were loaded on the external surface of HZSM-5, but some part of metallic species also block its micropores or entered its channels [39]. Since the loading of metals was almost the same and all the loadings were small $(<2 \mathrm{wt} \%)$, the pore volume and specific surface area of each metal-modified catalysts did not change by more than $10 \%$, which hardly affected the shape selectivity of the channel [40].

To further understand the chemical states of loaded metals on the catalyst, the XPS was performed on the catalysts without or with treatment with $\mathrm{H}_{2}$ at $873 \mathrm{~K}$ for $2 \mathrm{~h}$. As shown in Figure S3, the Zr-HZSM-5 catalyst presented peaks at the binding energy 182.9 and $185.2 \mathrm{eV}$, corresponding to the $\mathrm{ZrO}_{2}$ species. It is generally considered that $\mathrm{ZrO}_{2}$ is a non-reducible metal oxide. Nevertheless, its lattice oxygen or surface $\mathrm{OH}$ groups can be partially removed during high temperature (>893 K) reductive treatment [5], resulting a slight peak shift of $0.1 \mathrm{eV}$ towards the lower binding energies. Considering the Co or 
Mo species is very easily reduced to $\mathrm{Co}^{0}$ or $\mathrm{Mo}^{0}$ at a temperature of $673 \mathrm{~K}$ [41], it is very interesting that there is no $\mathrm{Co}^{0}(778.3$ and $793.3 \mathrm{eV})$ or $\mathrm{Mo}^{0}$ in the reduced catalyst. The main $\mathrm{Co}^{2+}$ and $\mathrm{Mo}^{4+}$ phases in the reduced catalysts could be taken as evidence of a strong interaction between metal species and HZSM- 5 zeolite. The Zn-HZSM-5 catalyst showed binding energy at 1024.1 and $1023.4 \mathrm{eV}$, attributed to $(\mathrm{ZnOH})^{+}$and exchangeable $\mathrm{Zn}^{2+}$ species, respectively. After being reduced by $\mathrm{H}_{2}$ at $873 \mathrm{~K}$, the XPS spectrum exhibited the decreased $(\mathrm{ZnOH})^{+}$species. The results showed a significant new peak at $1022.2 \mathrm{eV}$. The appearance of lower binding energy peak was dedicated to the $(\mathrm{ZnH})^{+}$species, generated by the hydrodehydroxylation of $(\mathrm{ZnOH})^{+}$species [42]. The binding energy for the reduced Ga-HZSM-5 (1118.6 eV) is higher than that for Ga-HZSM-5 (1118.4 eV). This increased in binding energy for the reduced Ga-HZSM- 5 is related to the strong interaction between the surface highly dispersed $(\mathrm{GaO})^{+}$species and the framework of the ZSM-5 zeolite. The stronger interaction between metal species and HZSM- 5 zeolite could promote the synergistic effect of dehydrogenation step and subsequent aromatization.

\subsection{Acidity of the Catalysts}

The $\mathrm{NH}_{3}$-TPD measurement was applied to investigate the acidity of the reduced catalysts. Compared to the as-synthesized HZSM-5, metal-loaded catalysts exhibited a significant difference in acidity. As shown in Figure $4 \mathrm{a}$, the $\mathrm{NH}_{3}$ desorption peaks of the metal-modified catalysts slightly shift towards a higher temperature, indicating an increase in strength for both strong and weak acid sites. Table 2 shows that the number of both weak acid sites and strong acid sites decreased with metal loading, but medium acid sites slightly increased. Compared with the HZSM-5, it seems that the amount of the medium acid sites increases markedly in the metal-modified HZSM- 5 at the expense of the strong and weak acid sites. The increased medium acid sites should be ascribed to the interactions between the metal species and the intrinsic acid sites in the parent HZSM-5 zeolite. Particularly for Co-, Mo-, and Zr-modified catalysts, the medium and strong acid sites significantly decreased to $0.21 \mathrm{mmol} \cdot \mathrm{g}^{-1}$ in comparison with Zn-HZSM-5 or Ga-HZSM-5 $\left(0.25 \mathrm{mmol} \cdot \mathrm{g}^{-1}\right)$ and as-synthesized HZSM-5 $\left(0.26 \mathrm{mmol} \cdot \mathrm{g}^{-1}\right)$.

Table 2. Acidic properties of the catalysts.

\begin{tabular}{ccccccc}
\hline \multirow{2}{*}{ Samples } & \multicolumn{2}{c}{ Acidity by $\mathbf{N H}_{\mathbf{3}}$-TPD $\left(\mathbf{m m o l} \cdot \mathbf{g}^{-\mathbf{1}}\right)$} & \multicolumn{3}{c}{ Acidity by Py-IR $\left(\boldsymbol{\mu m o l} \cdot \mathbf{g}^{-\mathbf{1})}\right.$} \\
\cline { 2 - 7 } & Weak Acid & Medium Acid & Strong Acid & BAS & LAS & B/L \\
\hline HZSM-5 & $0.28(51.85 \%)$ & $0.08(14.81 \%)$ & $0.18(33.34 \%)$ & 37.07 & 19.01 & 1.95 \\
Zr/HZSM-5 & $0.20(47.62 \%)$ & $0.09(21.43 \%)$ & $0.13(30.95 \%)$ & 35.84 & 19.80 & 1.81 \\
Co/HZSM-5 & $0.22(51.16 \%)$ & $0.11(25.58 \%)$ & $0.10(23.26 \%)$ & 34.69 & 20.47 & 1.70 \\
Mo/HZSM-5 & $0.23(51.11 \%)$ & $0.10(22.22 \%)$ & $0.12(26.67 \%)$ & 32.64 & 19.78 & 1.65 \\
Ga/HZSM-5 & $0.20(44.45 \%)$ & $0.11(24.44 \%)$ & $0.14(31.11 \%)$ & 24.47 & 19.50 & 1.26 \\
Zn/HZSM-5 & $0.26(50.98 \%)$ & $0.13(25.49 \%)$ & $0.12(23.53 \%)$ & 25.95 & 24.53 & 1.06 \\
\hline
\end{tabular}

The Py-IR results are shown in Figure 4b. The two peaks at around 1454 and $1545 \mathrm{~cm}^{-1}$ were attributed to Lewis acid sites (LAS) and Brønsted acid sites (BAS), respectively. Compared to HZSM-5, the Brønsted acid sites of metal-modified catalysts were decreased. The Brønsted acid sites of Zn- or Ga-modified HZSM- 5 were reduced to approximately $25 \mu \mathrm{mol} \cdot \mathrm{g}^{-1}$, which was $30 \%$ lower than that of HZSM-5. However, due to the Lewis acid sites created by the $\mathrm{Zn}$ species, the Lewis acid sites increased to $24 \mu \mathrm{mol} \cdot \mathrm{g}^{-1}$ for Zn-HZSM-5, resulting in the lowest B/L among all catalysts.

FTIR spectra in the hydroxyl stretching region provide more information about the acidic properties. As shown in Figure 4c, the large peak at $3610 \mathrm{~cm}^{-1}$ is associated with the framework $\mathrm{Si}(\mathrm{OH}) \mathrm{Al}$ structure, which is ascribed to Brønsted acid groups. The peak at $3656 \mathrm{~cm}^{-1}$ is attributed to an $\mathrm{OH}$ group on an extra-framework $\mathrm{Al}$ species. The intense and sharp peak at $3745 \mathrm{~cm}^{-1}$ is assigned to isolated silanol groups located on the external surface, the peak at $3728 \mathrm{~cm}^{-1}$ corresponding to free internal silanol group, and the small peak at $3686 \mathrm{~cm}^{-1}$ is ascribed to vicinal silanol groups located inside the micropores. The 
strong broad peak centered at $3500 \mathrm{~cm}^{-1}$ is generally attributed to nest silanol groups, which generally occur at crystal steps or extended defects [14]. The presence of such silanol groups is diagnostic for the presence of defect sites. Such defect sites in zeolite could promote the metallic species located in micropores of zeolites. It is interesting that although the external surface silanol groups $\left(3745 \mathrm{~cm}^{-1}\right)$ are less affected by introducing metal species, the silanol group with IR absorption bands at 3728,3686 , and $3610 \mathrm{~cm}^{-1}$ are changed considerably. This indicated that metallic species also could entered its micropores channels, which is agreement with $\mathrm{N}_{2}$ adsorption results (Table 1). In particular, the vibrational intensity at $3610 \mathrm{~cm}^{-1}$ is decreased by $26 \%$ for Ga-HZSM-5, suggesting the consumption of protons by introducing the metal species. Such phenomena were attributed to the interaction between the internal silanol groups and metal species located in the cationic positions of HZSM- 5 zeolite.

Figure $4 \mathrm{~d}$ shows the ${ }^{27} \mathrm{Al}$ MAS NMR spectra of the catalysts. The intense and sharp signal at $54 \mathrm{ppm}$ is dominant in all the spectra which is ascribed to the tetrahedral framework $\mathrm{Al}$ species, and the weak signals at $0 \mathrm{ppm}$ are attributed to octahedral extra-framework $\mathrm{Al}$ species. As shown in Figure 4d, the spectra of all the catalysts were very similar, this indicated that the framework structure was well maintained after metal modification. More specially, there was a little difference on framework Al signal (54 ppm), particularly for the peak intensity of $\mathrm{Zn}$ - or Ga-modified catalysts, the framework Al signal was obviously decreased, and the extra-framework $\mathrm{Al}$ signal increased. This could indicate that the metallic impregnation method had little influence on framework Al species. During the impregnating process, the stable framework $\mathrm{Al}$ atoms were first weakened by inserted metal atoms nearby, and then, $\mathrm{Al}$ atoms were expelled from the zeolite framework by calcination at high temperature. Xin et al. [43] also concluded that the introduction of an appropriate amount of tetrahedral framework Ga species could facilitate the framework distortion near the next-nearest neighbor framework $\mathrm{Al}$ sites, which caused dealumination during calcination, as evidenced by the increase in the intensity of octahedral extra-framework $\mathrm{Al}$ species. The difference of $\mathrm{Al}$ species determined by ${ }^{27} \mathrm{Al}$ MAS NMR could reflect the acidity of the zeolite catalysts, which is agreement with Py-IR and $\mathrm{NH}_{3}$-TPD results.

(a)
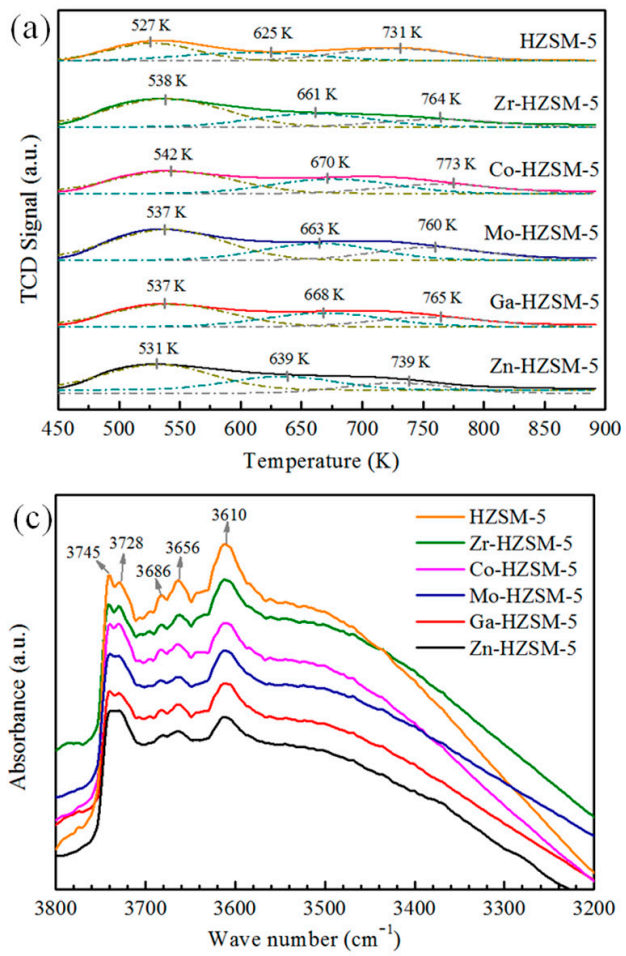
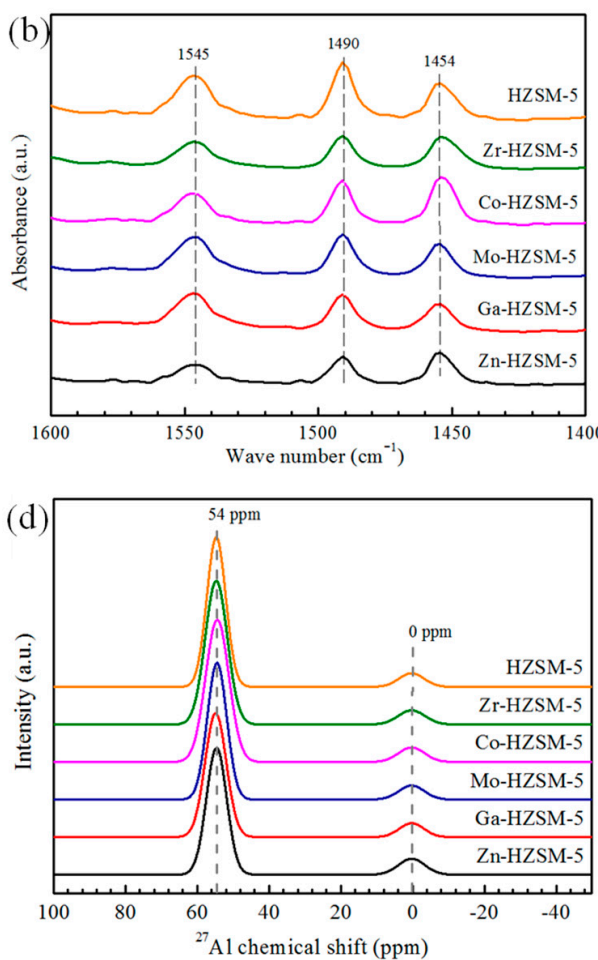

Figure 4. (a) $\mathrm{NH}_{3}$-TPD profiles, (b) Py-IR spectra, (c) FTIR spectra in hydroxyl group regions, (d) ${ }^{27} \mathrm{Al}$ MAS NMR spectra of the catalysts with hydrogen pre-treatment at $873 \mathrm{~K}$ for $2 \mathrm{~h}$. 
Figure 5 clearly shown that metal loading process has different influence on their acidity. More specifically, the acidic density of different metal-modified HZSM- 5 declined in the following order: HZSM-5 > Ga-HZSM-5 > Zn-HZSM-5 >> Mo-HZSM-5 > Zr-HZSM$5>$ Co-HZSM-5. However, the B/L of different metal-modified HZSM-5 declined in the following order: HZSM-5 > Zr-HZSM-5 > Co-HZSM-5 > Mo-HZSM-5 >> Ga-HZSM-5 > Zn-HZSM-5. In general, Zn- or Ga-modified HZSM-5 mainly reduced B/L and maintained their acidic density, while Mo, Co and Zr modified HZSM-5 significantly decreased medium and strong acidic density. The different change of catalysts acidity probably has a potential influence on propane conversion, particularly for product selectivity.

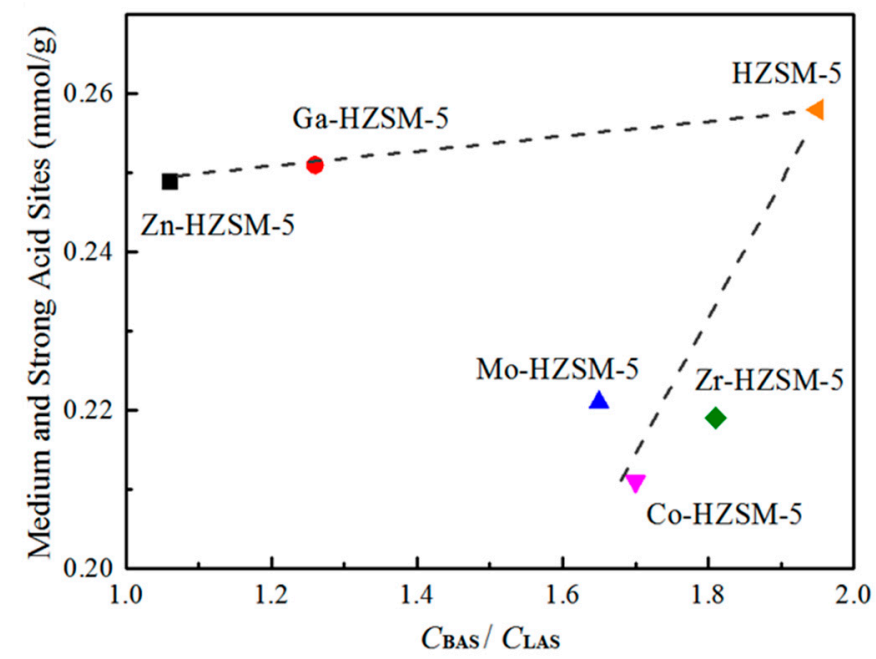

Figure 5. The influence of mental modification on acidity of catalysts.

\subsection{Propane Conversion on the Catalysts}

The propane conversion performance of the catalysts was investigated in a fixed-bed reactor at $873 \mathrm{~K}$ under $0.1 \mathrm{MPa}$ with WHSV $=2 \mathrm{~h}^{-1}$. It was well known that propane conversion takes place in medium and strong acid sites of the zeolite catalyst. As shown in Figure 6a, compared to the as-synthesized HZSM- 5 with a propane conversion of 55\%, the metal-loaded catalysts reduced propane conversion. Considering the low number of loaded metals (as seen in Table 1), the propane conversion decrease is mainly attributed to metal modification reducing the acid sites of the catalysts. More specifically, $\mathrm{Zn}$ - or Gamodified catalysts with $0.25 \mathrm{mmol} / \mathrm{g}$ medium and strong acid sites resulted in a propane conversion of $\sim 50 \%$. While for Mo or $\mathrm{Zr}$ modified catalysts, the medium and strong acid sites were reduced to $0.22 \mathrm{mmol} / \mathrm{g}$, and the propane conversion reduced to $\sim 40 \%$. Particularly for the Co-HZSM-5 catalyst with lowest medium and strong acid sites $(0.21 \mathrm{mmol} / \mathrm{g})$, propane conversion decreased to $\sim 25 \%$. Additionally, the propane conversion approximately followed a linear relationship with the medium and strong acid (Figure 6b), except Co-HZSM-5. It is well known that particle size and dispersion of the metal phase are key factors for achieving higher catalytic activity [25]. The Co-HZSM-5 catalyst exhibited an unexpected low propane conversion of $\sim 25 \%$, which is due to its large Co particle size and some Co species aggregates (Figure 3 ). These results suggested the existence of a balance between the acidity and metal size on propane conversion performance. 

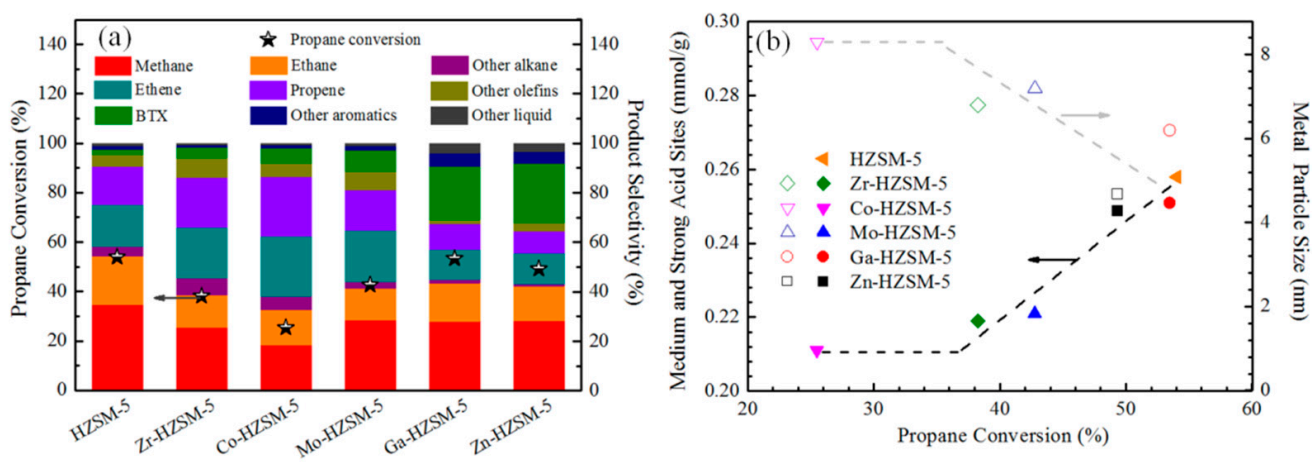

Figure 6. (a) Propane conversion and product selectivity over the catalysts; (b) the impact of medium and strong acid sites on propane conversion.

The detailed product distribution for the samples is also shown in Table 3. It can be seen that the products mainly contain methane, ethane, olefins and aromatics. In comparison with HZSM-5, the light alkanes decreased on metal-modified catalysts. Additionally, the selectivity of olefins increased in $\mathrm{Mo}-, \mathrm{Co}-$, and $\mathrm{Zr}$-modified catalysts, particularly for the Co-HZSM- 5 catalyst, with an olefin selectivity of $\sim 54 \%$. While for $\mathrm{Zn}$ - or Ga-modified HZSM-5, the selectivity of aromatics was $\sim 29 \%$ and $\sim 27 \%$, respectively, which is higher than that of other catalysts. It is well known that propane conversion on acidic ZSM-5 zeolites involves series of reactions such as dehydrogenation, cracking, oligomerization, aromatization, dealkylation and hydrogen transfer reactions. The reaction pathway and catalyst properties could be reflected by detailed product distribution. As shown in Figure 5, Mo-, Co- and Zr-modified HZSM-5 significantly decreased medium and strong acidic density. Therefore, the olefin aromatization was suppressed, resulting in a high selectivity of olefins (Figure 7), while Zn- or Ga-modified HZSM-5 maintained their acidic density, and mainly reduced $\mathrm{B} / \mathrm{L}$ due to the Lewis acid sites created by $\mathrm{Zn}$ or Ga species. Therefore, the olefins intermediates could further convert to aromatics on Zn-HZSM-5 or Ga-HZSM-5 catalyst (Figure 7). However, HZSM-5 catalyst has both high B/L and acidic density. A large number of Brønsted acid sites could accelerate the cracking of higher hydrocarbons, and thus decreases the selectivity of aromatics.

Table 3. The detailed products distribution of the catalysts ${ }^{\mathrm{a}}$.

\begin{tabular}{|c|c|c|c|c|c|c|}
\hline & HZSM-5 & Zr-HZSM-5 & Co-HZSM-5 & Mo-HZSM-5 & Ga-HZSM-5 & Zn-HZSM-5 \\
\hline Methane $\left(C_{1}\right)$ & 34.76 & 25.57 & 18.24 & 28.36 & 28.02 & 28.15 \\
\hline Ethane $\left(C_{2}\right)$ & 19.47 & 13.02 & 14.35 & 12.93 & 15.43 & 14.03 \\
\hline Ethene $\left(C_{2}=\right)$ & 17.17 & 20.55 & 24.17 & 20.83 & 11.93 & 12.71 \\
\hline Propene $\left(C_{3}=\right)$ & 15.27 & 20.21 & 24.14 & 16.27 & 10.54 & 8.76 \\
\hline Butane $\left(C_{4}\right)$ & 3.71 & 6.69 & 5.38 & 2.41 & 1.43 & 0.61 \\
\hline Butene $\left(\mathrm{C}_{4}=\right.$ & 4.02 & 5.46 & 4.66 & 3.57 & 1.31 & 1.88 \\
\hline Pentane $\left(\mathrm{C}_{5}\right)$ & 0.19 & 0.21 & 0.17 & 0.21 & 0.10 & 0.14 \\
\hline Pentene $\left(C_{5}=\right)$ & 0.71 & 2.34 & 0.68 & 4.07 & 0.27 & 1.44 \\
\hline Benzene $\left(\mathrm{C}_{6}\right)$ & 0.36 & 1.72 & 2.01 & 2.07 & 5.10 & 5.62 \\
\hline Toluene $\left(C_{7}\right)$ & 1.41 & 1.42 & 3.22 & 4.39 & 11.93 & 13.91 \\
\hline Xylene $\left(C_{8}\right)$ & 0.55 & 1.06 & 1.14 & 2.02 & 4.45 & 4.47 \\
\hline Ethylbenzene $\left(C_{8}\right)$ & 0.08 & 0.03 & 0.06 & 0.16 & 0.39 & 0.07 \\
\hline $\mathrm{C}_{9}$ & 0.39 & 0.54 & 0.31 & 0.53 & 1.15 & 1.43 \\
\hline $\mathrm{C}_{10}$ & 0.11 & 0.22 & 0.16 & 0.25 & 0.84 & 0.43 \\
\hline $\mathrm{C}_{>10}$ & 0.78 & 0.15 & 0.60 & 0.89 & 3.27 & 3.04 \\
\hline Other liquids & 1.01 & 0.80 & 0.66 & 1.01 & 3.81 & 3.26 \\
\hline Carbon balance $\%$ & 99.99 & 99.99 & 99.95 & 99.97 & 99.97 & 99.95 \\
\hline
\end{tabular}

a The data were obtained after an $8 \mathrm{~h}$ reaction. 

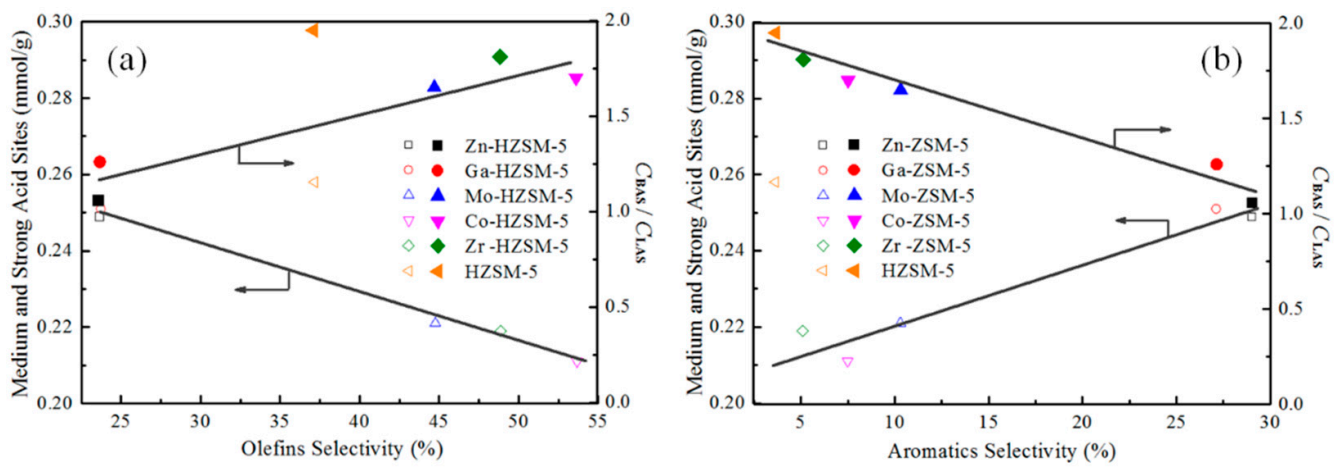

Figure 7. The impact of acidity on (a) olefins selectivity and (b) aromatics selectivity.

During propane conversion reaction, light alkanes mainly produced from cracking, dealkylation and hydrogen transfer reactions. As shown in Figure 8a, the light alkanes selectivity approximately followed a linear relationship with the medium and strong acidic density for Mo, Co, and Zr modified ZSM-5, except Zn- or Ga-modified ZSM-5. In particular, the medium and strong acidic density of Zn- or Ga-modified ZSM-5 was $0.026 \mathrm{mmol} / \mathrm{g}$ more than that of Mo- or Zr-modified ZSM-5, while the alkane selectivity was nearly the same (44-45\%). It is well known that cracking and hydrogen transfer reactions mainly occurred in the center of Brønsted acid sites; however, the dealkylation and dehydrogenation reactions largely occurred in the centre of Lewis acid sites [17]. As exhibited in Table 2, Zn- or Ga-modified ZSM-5 decreased Brønsted acid sites, so that the cracking and hydrogen transfer reactions were suppressed, resulting lower alkane selectivity than HZSM-5. However, as shown in Figure 8b, the Brønsted acid sites of Znor Ga-modified ZSM-5 were 19 umol/g less than that of Mo- or Zr-modified ZSM-5. For Zn- or Ga-modified ZSM-5, the cracking and hydrogen transfer reactions were obviously suppressed, but the alkane selectivity was still high. This is because dehydrogenation reactions largely occur in the center of the Lewis acid sites that are created by $\mathrm{Zn}$ or Ga species. A large amount of aromatics was formed via olefins intermediates (Figure 7) by dehydrogenation pathway. At the same time, it also accelerated the dealkylation and cracking of higher hydrocarbons, and thus increased the selectivity of light alkanes.
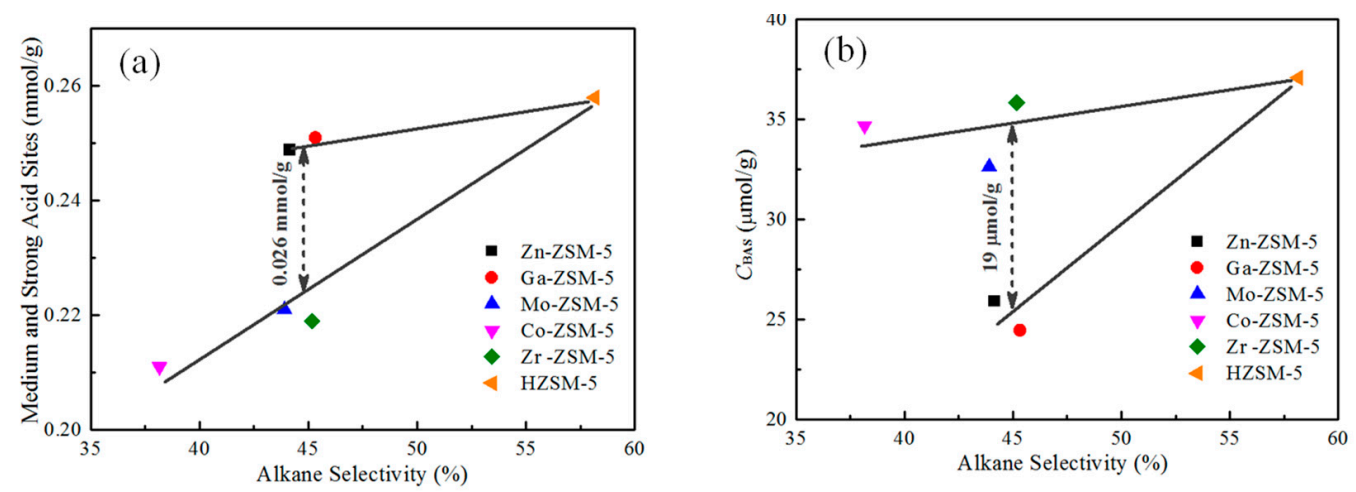

Figure 8. The impact of medium and strong acid sites (a), and Brønsted acid sites (b) on alkane selectivity.

As shown in Figure 9, the reaction mechanism of propane conversion over metalmodified HZSM-5 was proposed. Generally, zeolite catalysts could activate propane to produce propene and ethene though dehydrogenation and cracking reactions, respectively. Then, oligomerization, cyclization of the propene and ethene to produce aromatics on acid sites of zeolite. The oligomerization, cracking and hydrogen transfer reactions mainly occurred in the center of Brønsted acid sites; however, the dealkylation and dehydrogenation reactions largely occurred in the center of Lewis acid sites. After metal modification, the medium and strong acid sites were reduced, particularly for Brønsted acid sites, result- 
ing less propane cracking. Moreover, Mo-, Co- and Zr-modified HZSM-5 significantly decreased medium and strong acidic density. Therefore, olefin aromatization (including oligomerization, cyclization, and hydrogen transfer reactions) was suppressed, resulting in the high selectivity of olefins, while Zn- or Ga-modified HZSM-5 maintained their acidic density, and mainly reduced B/L due to the Lewis acid sites created by Zn or Ga species. A large amount of Lewis acid sites is beneficial to promote the dehydrogenation reaction, which is favorable to increase the selectivity of aromatics. However, the oligomerization and hydrogen transfer reactions will be limited due to the lack of Brønsted acid sites, which also inhibits the production of aromatic hydrocarbons.

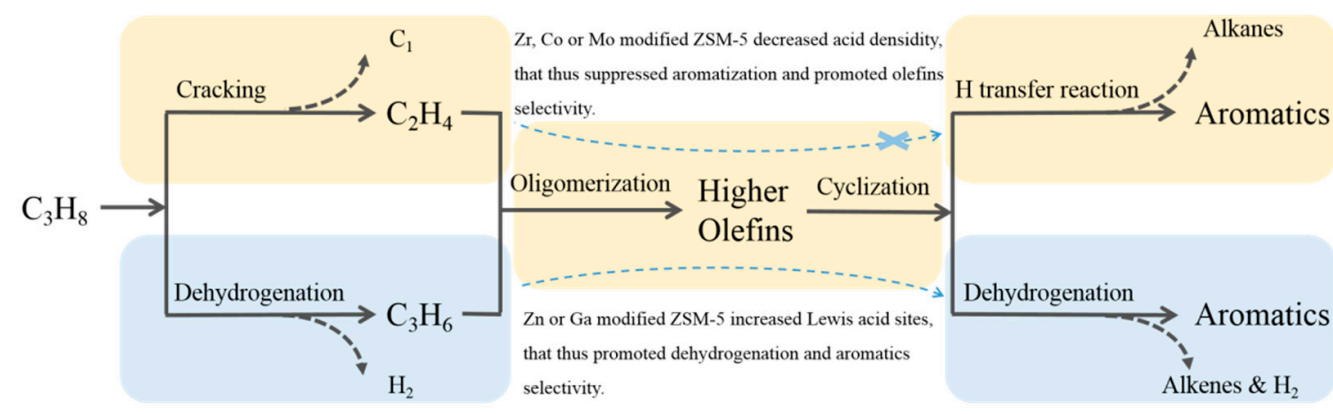

The yellow part including cracking, oligomerization and $\mathrm{H}$ transfer reactions, that is mainly influenced by Brønsted acid sites.

The blue part including propane dehydrogenation and olefins aromatization, that is mostly influenced by Lewis acid sites.

Figure 9. Diagram of the reaction mechanism of propane conversion over metal-modified HZSM-5.

\section{Materials and Methods}

\subsection{Catalyst Preparation}

HZSM-5 zeolite used in this work was purchased from the NanKai University Catalyst Co., Ltd. (Tianjin, China), and the $\mathrm{SiO}_{2} / \mathrm{Al}_{2} \mathrm{O}_{3}$ ratio of the zeolite was 61 (detected by ICP-AES, Thermo Fisher Scientific, Waltham, MA, USA). The metal loaded catalysts were prepared via incipient wetness impregnation technique with the metal content of $2 \mathrm{wt} \%$. Specifically, HZSM- 5 zeolite was pressed, crushed, and sorted to obtain particles of 20-40 mesh, and then dried in an oven at $423 \mathrm{~K}$ for $6 \mathrm{~h}$. Then, $50 \mathrm{~g}$ HZSM- 5 was mixed with $50 \mathrm{~mL}$ aqueous solution of metal precursors at room temperature for $24 \mathrm{~h}$ and impregnated in a water bath at $353 \mathrm{~K}$ for $3 \mathrm{~h}$. The impregnated zeolite was then dried at $383 \mathrm{~K}$ overnight and calcined in an oven at $823 \mathrm{~K}$ for $6 \mathrm{~h}$ to obtain the M/HZSM- 5 samples. The metal precursors used were $\mathrm{Zr}\left(\mathrm{NO}_{3}\right)_{4} \cdot 5 \mathrm{H}_{2} \mathrm{O}, \mathrm{Co}\left(\mathrm{NO}_{3}\right)_{2} \cdot 6 \mathrm{H}_{2} \mathrm{O},\left(\mathrm{NH}_{4}\right)_{6} \mathrm{Mo}_{7} \mathrm{O}_{24} \cdot 4 \mathrm{H}_{2} \mathrm{O}, \mathrm{Ga}\left(\mathrm{NO}_{3}\right)_{3} \cdot 9 \mathrm{H}_{2} \mathrm{O}$, or $\mathrm{Zn}\left(\mathrm{NO}_{3}\right)_{2} \cdot 6 \mathrm{H}_{2} \mathrm{O}$ and were purchased from Sinopharm Chemical Reagent Co., Ltd. (Shanghai, China). The modified HZSM-5 with $2 \mathrm{wt} \%$ metal was denoted as M-HZSM-5 $(\mathrm{M}=\mathrm{Zr}, \mathrm{Co}, \mathrm{Mo}, \mathrm{Ga}$, or $\mathrm{Zn})$.

\subsection{Catalyst Characterization}

The powder X-ray diffraction (XRD, D8 Advance, Bruker, Germany) analysis was acquired to identify the type of crystalline phase and crystallinity of the reduced catalysts. XRD used $\mathrm{Cu} \mathrm{K} \alpha$ radiation $(\lambda=1.54439 \AA)$ at $40 \mathrm{kV}$ and $100 \mathrm{~mA}$ in the $2 \theta$ range of $5-50^{\circ}$. The crystallinity was calculated as ratio of peak area in the range of $2 \theta=8.0-10.0^{\circ}$ and 23.0-25. $0^{\circ}$ to that of the HZSM-5 sample.

The morphology of the reduced samples was measured by SEM (JSM 7001-F, JEOL, Japan). The textual properties of the reduced samples were investigated using a Micromeritics ASAP 2010 instrument. Before the measurements, the samples were heated to $493 \mathrm{~K}$ in a vacuum for $12 \mathrm{~h}$. Nitrogen adsorption/desorption isotherms were measured at $77 \mathrm{~K}$.

The TEM images were investigated using a JEM-2100F (JEOL, Japan) with an accelerating voltage of $200 \mathrm{kV}$. The reduced samples suspended in ethanol solutions were dipped onto carbon-coated copper grids and then dried in ambient conditions.

The inductively coupled plasma-atomic emission spectrometer (ICP-AES, Thermo Icap 6300 , Thermo Fisher Scientific, Waltham, MA, USA) was used to determine the chemical 
compositions of the reduced samples. Before measurement, a $0.1 \mathrm{~g}$ sample was dissolved in the mixture solutions with $0.5 \mathrm{~mL}$ hydrofluoric acid (40 wt\%) and $2 \mathrm{~mL}$ nitric acid (65 wt $\%$ ) at $333 \mathrm{~K}$.

The X-ray photoelectron spectroscopy (XPS, AXIS ULTRA DLD, Kratos, England) was carried out using $\mathrm{Mg} \mathrm{K} \alpha(\lambda=1253.6 \mathrm{eV})$. The binding energies were calibrated relative to the $\mathrm{C} 1 \mathrm{~s}$ peak from carbon contamination at $284.6 \mathrm{eV}$. The pressure of the analysis chamber was less than $2 \times 10^{-8} \mathrm{~Pa}$.

The ${ }^{27}$ Al MAS NMR spectra were recorded on an Avance III $600 \mathrm{MHz}$ spectrometer (Bruker, Switzerland). $\mathrm{Al}\left(\mathrm{NO}_{3}\right)_{3}$ solutions were used as reference of the chemical shifts for ${ }^{27}$ Al MAS NMR.

The acid properties of the reduced samples were determined by $\mathrm{NH}_{3}$-TPD (Autochem II 2920 instrument, Micromeritics, USA). The sample was first activated at $823 \mathrm{~K}$ for $2 \mathrm{~h}$ in argon flow ( $30 \mathrm{~mL} \mathrm{~min}^{-1}$ ) and then cooled to $393 \mathrm{~K} . \mathrm{NH}_{3}$ adsorption on the sample was then achieved by introducing gaseous $\mathrm{NH}_{3}\left(5 \mathrm{vol} \%\right.$ in argon, $\left.30 \mathrm{~mL} \mathrm{~min}{ }^{-1}\right)$ for $0.5 \mathrm{~h}$. After that, the physically adsorbed $\mathrm{NH}_{3}$ was removed by argon flow $\left(30 \mathrm{~mL} \mathrm{~min}^{-1}\right)$ at $393 \mathrm{~K}$ for $2 \mathrm{~h}$. To get the $\mathrm{NH}_{3}$-TPD profile, the zeolite sample was then heated from 393 to $923 \mathrm{~K}$ with a heating rate of $10.0 \mathrm{~K} \mathrm{~min}^{-1}$.

The spectra of the surface hydroxyl vibrations were measured on a Tensor 27 FT-IR spectrometer (Bruker, Germany). Fourier-transform infrared spectra of adsorbed pyridine (Py-IR) were also collected on Tensor 27 FT-IR spectrometer from Bruker. Specifically, the reduced sample was pressed into a pellet (diameter: $13 \mathrm{~mm}$, weight: ca. $30 \mathrm{mg}$ ) and activated at $673 \mathrm{~K}$ for $90 \mathrm{~min}$ under vacuum of $10^{-2} \mathrm{~Pa}$, and then the IR spectra were recorded at room temperature. Pyridine vapor was introduced into the sample cell at room temperature for $30 \mathrm{~min}$, followed by evacuation at $673 \mathrm{~K}$ for $30 \mathrm{~min}$. Then, the spectra were recorded after evacuation. The spectra of adsorbed pyridine species can be obtained by subtracting the background spectra.

\subsection{Propane Conversion Testing}

Propane conversion was evaluated in a continuous-flow, fixed-bed stainless-steel reactor (16 $\mathrm{mm}$ I.D.) at $873 \mathrm{~K}$ under $0.1 \mathrm{MPa}$. The reaction temperature was measured by a thermocouple in the center of the catalyst bed. Prior to the reaction, catalyst pellets ( $5 \mathrm{~g}$, 20-40 mesh) were placed in the reactor. Then, the catalyst was pre-treated at $873 \mathrm{~K}$ for $3 \mathrm{~h}$ with $\mathrm{H}_{2}$ flow of $100 \mathrm{~mL} \mathrm{~min}^{-1}$. After that, propane was introduced into the reactor with the gas hourly space velocity (GHSV) of $700 \mathrm{~h}^{-1}$. The reaction products were passed through a condenser, and then the liquid products can be obtained separately. The vapor stream was then passed through an Agilent 7890A (Agilent Technologies Inc., Santa Clara, CA, USA) equipped with a thermal conductivity detector (TCD) and a flame ionization detector (FID) for online analysis. The liquid products were analyzed with a SHIMADZU GC-2014C gas chromatography (Shimadzu, Japan) equipped with an FID. The conversion of propane and the product selectivity were calculated following Equations (1) and (2), respectively.

$$
\begin{aligned}
& C_{\text {propane }}=\frac{\text { Moles of propane reated }}{\text { Moles of propane fed }} \times 100 \% \\
& S_{\text {product }}=\frac{\text { Moles of product formed }}{\text { Moles of propane reacted }} \times 100 \%
\end{aligned}
$$

\section{Conclusions}

The catalytic properties of a series of metal modified HZSM- 5 zeolite catalysts (i.e., $\mathrm{Zn}, \mathrm{Ga}, \mathrm{Mo}, \mathrm{Co}$, and $\mathrm{Zr}$ ) for propane conversion were evaluated. It was found that the loaded metals were uniform in distribution, except the Co species with some aggregates. It was also found that the balance between metal size and the acidity of zeolite existed on propane conversion. High propane conversion was achieved by decreasing metal size and increasing acidity, e.g., ZnHZSM-5 and Ga-HZSM-5, while Co-HZSM-5 exhibited low propane conversion due to its low acidity and large Co size with some aggregates. 
The metal impregnation process obviously has a different influence on framework $\mathrm{Al}$ species and the acidity of zeolites. After metal modification, the framework Al obviously decreased, and the extra-framework $\mathrm{Al}$ increased, resulting in strong acid sites decreasing, particularly for Brønsted acid sites. Thus, less propane cracking occurred. Moreover, the changes of catalytic acidity had a significant influence on the reaction mechanism of propane conversion, resulting in different product selectivity. Mo-, Co- and Zr-modified HZSM-5 significantly decreased medium and strong acidic density; thus, oligomerization, cyclization, and hydrogen transfer reactions were suppressed, resulting in a high level of selectivity for olefins, while Zn- or Ga-modified HZSM-5 maintained acidic density, and mainly reduced B/L due to the Lewis acid sites created by $\mathrm{Zn}$ or Ga species. These increased Lewis acid sites are beneficial for the promotion of aromatic selectivity via the dehydrogenation pathway.

Supplementary Materials: The following are available online at https:/ /www.mdpi.com/article/10 $.3390 /$ catal11101138/s1, Figure S1: The particle size distribution of the catalysts from SEM images. (a): HZSM-5; (b): Zr-HZSM-5; (c): Co-HZSM-5; (d): Mo-HZSM-5; (e): Ga-HZSM-5: (f): Zn-HZSM-5.; Figure S2: The particle size distribution of the loaded metals from TEM images. (a): Zr/HZSM-5; (b): Co/HZSM-5; (c): Mo/HZSM-5; (d): Ga/HZSM-5: (e): Zn/HZSM-5; Figure S3: The XPS spectra of the catalysts.

Author Contributions: Conceptualization, K.J.; methodology, H.Z.; software, F.Z.; validation, F.Z., J.G., K.Z. and K.J.; investigation, F.Z.; resources, K.Z.; data curation, F.Z.; writing-original draft preparation, H.Z.; writing - review and editing, H.Z.; visualization, H.Z., F.Z. and S.W.; supervision, P.L. and K.Z.; project administration, P.L. and K.Z.; funding acquisition, P.L., K.Z. and J.G. All authors have read and agreed to the published version of the manuscript.

Funding: This research was funded by the Key technical talents program of Chinese Academy of Sciences (YB2021001).

Acknowledgments: The authors acknowledge the financial support from the Key technical talents program of Chinese Academy of Sciences (YB2021001).

Conflicts of Interest: The authors declare no conflict of interest.

\section{References}

1. Schwach, P.; Pan, X.; Bao, X. Direct Conversion of Methane to Value-Added Chemicals over Heterogeneous Catalysts: Challenges and Prospects. Chem. Rev. 2017, 117, 8497-8520. [CrossRef]

2. Zhou, H.; Yi, X.F.; Hui, Y.; Wang, L.; Chen, W.; Qin, Y.C.; Wang, M.; Ma, J.B.; Chu, X.F.; Wang, Y.Q.; et al. Isolated boron in zeolite for oxidative dehydrogenation of propane. Science 2021, 372, 76-80. [CrossRef]

3. Wang, G.; Li, C.; Shan, H. Catalytic dehydrogenation of isobutane over a $\mathrm{Ga}_{2} \mathrm{O}_{3} / \mathrm{ZnO}$ interface: Reaction routes and mechanism. Catal. Sci. Technol. 2016, 6, 3128-3136. [CrossRef]

4. Ma, F.; Chang, Q.-Y.; Yin, Q.; Sui, Z.-J.; Zhou, X.-G.; Chen, D.; Zhu, Y.-A. Rational screening of single-atom-doped ZnO catalysts for propane dehydrogenation from microkinetic analysis. Catal. Sci. Technol. 2020, 10, 4938-4951. [CrossRef]

5. Han, S.; Otroshchenko, T.; Zhao, D.; Lund, H.; Rockstroh, N.; Vuong, T.H.; Rabeah, J.; Rodemerck, U.; Linke, D.; Gao, M.; et al. The effect of $\mathrm{ZrO}_{2}$ crystallinity in $\mathrm{CrZrO}_{\mathbf{x}} / \mathrm{SiO}_{2}$ on non-oxidative propane dehydrogenation. Appl. Catal. A Gen. 2020, 590, 117350. [CrossRef]

6. Hu, Z.-P.; Yang, D.; Wang, Z.; Yuan, Z.-Y. State-of-the-art catalysts for direct dehydrogenation of propane to propylene. Chin. J. Catal. 2019, 40, 1233-1254. [CrossRef]

7. Sattler, J.J.H.B.; Ruiz-Martinez, J.; Santillan-Jimenez, E.; Weckhuysen, B.M. Catalytic Dehydrogenation of Light Alkanes on Metals and Metal Oxides. Chem. Rev. 2014, 114, 10613-10653. [CrossRef] [PubMed]

8. Sun, Q.; Wang, N.; Fan, Q.; Zeng, L.; Mayoral, A.; Miao, S.; Yang, R.; Jiang, Z.; Zhou, W.; Zhang, J.; et al. Subnanometer Bimetallic Platinum-Zinc Clusters in Zeolites for Propane Dehydrogenation. Angew. Chem. Int. Ed. 2020, 59, 19450-19459. [CrossRef] [PubMed]

9. Chen, C.; Sun, M.; Hu, Z.; Ren, J.; Zhang, S.; Yuan, Z.-Y. New insight into the enhanced catalytic performance of ZnPt/HZSM-5 catalysts for direct dehydrogenation of propane to propylene. Catal. Sci. Technol. 2019, 9, 1979-1988. [CrossRef]

10. Kim, K.; Ryoo, R.; Jang, H.-D.; Choi, M. Spatial distribution, strength, and dealumination behavior of acid sites in nanocrystalline MFI zeolites and their catalytic consequences. J. Catal. 2012, 288, 115-123. [CrossRef]

11. Lin, L.F.; Zhao, S.F.; Zhang, D.W.; Fan, H.; Liu, Y.M.; He, M.Y. Acid Strength Controlled Reaction Pathways for the Catalytic Cracking of 1-Pentene to Propene over ZSM-5. ACS Catal. 2015, 5, 4048-4059. [CrossRef] 
12. Zhao, S.; Yang, D.; Zhang, X.; Yao, X.; Liu, Y.; He, M. ZSM-5 with controllable acidity as an efficient catalyst for a highly adjustable propene/ethene ratio in the 1-butene cracking. Chem. Commun. 2016, 52, 11191-11194. [CrossRef]

13. Gim, M.Y.; Song, C.; Lim, Y.H.; Lee, K.-Y.; Kim, D.H. Effect of the Si/Al ratio in Ga/mesoporous HZSM-5 on the production of benzene, toluene, and xylene via coaromatization of methane and propane. Catal. Sci. Technol. 2019, 9, 6285-6296. [CrossRef]

14. Shao, J.; Fu, T.; Li, Z. The selective and stable synthesis of aromatics from methanol via two-step route using light alkenes as intermediates. Fuel 2020, 280, 118609. [CrossRef]

15. Fu, T.; Shao, J.; Li, Z. Catalytic synergy between the low Si / Al ratio Zn/ZSM-5 and high Si/Al ratio HZSM-5 for high performance methanol conversion to aromatics. Appl. Catal. B Environ. 2021, 291, 120098. [CrossRef]

16. Yarulina, I.; De Wispelaere, K.; Bailleul, S.; Goetze, J.; Radersma, M.; Abou-Hamad, E.; Vollmer, I.; Goesten, M.; Mezari, B.; Hensen, E.J.M.; et al. Structure-performance descriptors and the role of Lewis acidity in the methanol-to-propylene process. Nat. Chem. 2018, 10, 804-812. [CrossRef] [PubMed]

17. Jia, Y.; Wang, J.; Zhang, K.; Feng, W.; Liu, S.; Ding, C.; Liu, P. Nanocrystallite self-assembled hierarchical ZSM-5 zeolite microsphere for methanol to aromatics. Microporous Mesoporous Mater. 2017, 247, 103-115. [CrossRef]

18. Wannapakdee, W.; Yutthalekha, T.; Dugkhuntod, P.; Rodponthukwaji, K.; Thivasasith, A.; Nokbin, S.; Witoon, T.; Pengpanich, S.; Wattanakit, C. Dehydrogenation of Propane to Propylene Using Promoter-Free Hierarchical Pt/Silicalite-1 Nanosheets. Catalysts 2019, 9, 174. [CrossRef]

19. Zhou, W.; Liu, J.; Wang, J.; Lin, L.; He, N.; Zhang, X.; Guo, H. Transformation of Propane over ZnSnPt Modified Defective HZSM-5 Zeolites: The Crucial Role of Hydroxyl Nests Concentration. Catalysts 2019, 9, 571. [CrossRef]

20. Arzumanov, S.S.; Gabrienko, A.A.; Freude, D.; Stepanov, A.G. Competitive pathways of methane activation on $\mathrm{Zn}^{2+}$-modified ZSM-5 zeolite: H/D hydrogen exchange with Bronsted acid sites versus dissociative adsorption to form Zn-methyl species. Catal. Sci. Technol. 2016, 6, 6381-6388. [CrossRef]

21. Luo, Y.; Miao, C.; Yue, Y.; Hua, W.; Gao, Z. ZnO supported on Silicalite-1 as an efficient catalyst for isobutane dehydrogenation to isobutene assisted by $\mathrm{CO}_{2}$. Microporous Mesoporous Mater. 2020, 294, 109864. [CrossRef]

22. Ivanova, I.I.; Kolyagin, Y.G.; Ordomsky, V.V.; Asachenko, E.V.; Pasynkova, E.M.; Pirogov, Y.A. Surface species formed during propane aromatization over Zn/MFI catalyst as determined by in situ spectroscopic techniques. J. Mol. Catal. A Chem. 2009, 305, 47-53. [CrossRef]

23. Zhang, Y.; Zhou, Y.; Huang, L.; Zhou, S.; Sheng, X.; Wang, Q.; Zhang, C. Structure and catalytic properties of the Zn-modified ZSM-5 supported platinum catalyst for propane dehydrogenation. Chem. Eng. J. 2015, 270, 352-361. [CrossRef]

24. Salaeva, A.A.; Salaev, M.A.; Vodyankina, O.V.; Mamontov, G.V. Synergistic effect of Cu and Zn modifiers on the activity of $\mathrm{CrO}_{\mathrm{x}} / \mathrm{Al}_{2} \mathrm{O}_{3}$ catalysts in isobutane dehydrogenation. Appl. Catal. A Gen. 2019, 581, 82-90. [CrossRef]

25. Zhao, D.; Li, Y.; Han, S.; Zhang, Y.; Jiang, G.; Wang, Y.; Guo, K.; Zhao, Z.; Xu, C.; Li, R.; et al. ZnO Nanoparticles Encapsulated in Nitrogen-Doped Carbon Material and Silicalite-1 Composites for Efficient Propane Dehydrogenation. iScience 2019, 13, 269-276. [CrossRef] [PubMed]

26. Xiao, H.; Zhang, J.; Wang, X.; Zhang, Q.; Xie, H.; Han, Y.; Tan, Y. A highly efficient Ga/ZSM-5 catalyst prepared by formic acid impregnation and in situ treatment for propane aromatization. Catal. Sci. Technol. 2015, 5, 4081-4090. [CrossRef]

27. Hensen, E.J.M.; Pidko, E.A.; Rane, N.; van Santen, R.A. Water-Promoted Hydrocarbon Activation Catalyzed by Binuclear Gallium Sites in ZSM-5 Zeolite. Angew. Chem. Int. Ed. 2007, 46, 7273-7276. [CrossRef]

28. Rodrigues, V.d.O.; Faro Júnior, A.C. On catalyst activation and reaction mechanisms in propane aromatization on Ga/HZSM5 catalysts. Appl. Catal. A Gen. 2012, 435-436, 68-77. [CrossRef]

29. Kim, W.-G.; So, J.; Choi, S.-W.; Liu, Y.; Dixit, R.S.; Sievers, C.; Sholl, D.S.; Nair, S.; Jones, C.W. Hierarchical Ga-MFI Catalysts for Propane Dehydrogenation. Chem. Mater. 2017, 29, 7213-7222. [CrossRef]

30. Choi, S.-W.; Kim, W.-G.; So, J.-S.; Moore, J.S.; Liu, Y.; Dixit, R.S.; Pendergast, J.G.; Sievers, C.; Sholl, D.S.; Nair, S.; et al. Propane dehydrogenation catalyzed by gallosilicate MFI zeolites with perturbed acidity. J. Catal. 2017, 345, 113-123. [CrossRef]

31. Wang, L.; Tao, L.; Xie, M.; Xu, G.; Huang, J.; Xu, Y. Dehydrogenation and aromatization of methane under non-oxidizing conditions. Catal. Lett. 1993, 21, 35-41. [CrossRef]

32. Choudhary, V.R.; Mondal, K.C.; Mulla, S.A.R. Simultaneous Conversion of Methane and Methanol into Gasoline over Bifunctional Ga-, Zn-, In-, and/or Mo-Modified ZSM-5 Zeolites. Angew. Chem. Int. Ed. 2005, 117, 4455-4459. [CrossRef]

33. Watanabe, R.; Hirata, N.; Miura, K.; Yoda, Y.; Fushimi, Y.; Fukuhara, C. Formation of active species for propane dehydrogenation with hydrogen sulfide co-feeding over transition metal catalyst. Appl. Catal. A Gen. 2019, 587, 117238. [CrossRef]

34. Zhang, Y.; Zhao, Y.; Otroshchenko, T.; Lund, H.; Pohl, M.-M.; Rodemerck, U.; Linke, D.; Jiao, H.; Jiang, G.; Kondratenko, E.V. Control of coordinatively unsaturated $\mathrm{Zr}$ sites in $\mathrm{ZrO}_{2}$ for efficient $\mathrm{C}-\mathrm{H}$ bond activation. Nat. Commun. 2018, 9, $3794-3804$. [CrossRef] [PubMed]

35. Otroshchenko, T.; Bulavchenko, O.; Thanh, H.V.; Rabeah, J.; Bentrup, U.; Matvienko, A.; Rodemerck, U.; Paul, B.; Kraehnert, R.; Linke, D.; et al. Controlling activity and selectivity of bare $\mathrm{ZrO}_{2}$ in non-oxidative propane dehydrogenation. Appl. Catal. A Gen. 2019, 585, 117189. [CrossRef]

36. Jeon, N.; Choe, H.; Jeong, B.; Yun, Y. Cu-promoted zirconia catalysts for non-oxidative propane dehydrogenation. Appl. Catal. A Gen. 2019, 586, 117211. [CrossRef]

37. Tshabalala, T.E.; Scurrell, M.S. Aromatization of n-hexane over Ga, Mo and Zn modified H-ZSM-5 zeolite catalysts. Catal. Commun. 2015, 72, 49-52. [CrossRef] 
38. Majhi, S.; Dalai, A.K.; Pant, K.K. Methanol assisted methane conversion for higher hydrocarbon over bifunctional Zn-modified Mo/HZSM-5 catalyst. J. Mol. Catal. A Chem. 2015, 398, 368-375. [CrossRef]

39. Hu, C.; Li, J.; Jia, W.; Liu, M.; Hao, Z.; Zhu, Z. Influence of Metallic Modification on Ethylbenzene Dealkylation over ZSM-5 Zeolites. Chin. J. Chem. 2015, 33, 247-252. [CrossRef]

40. Xu, C.; Jiang, B.; Liao, Z.; Wang, J.; Huang, Z.; Yang, Y. Effect of metal on the methanol to aromatics conversion over modified ZSM-5 in the presence of carbon dioxide. RSC Adv. 2017, 7, 10729-10736. [CrossRef]

41. Xing, C.; Yang, G.; Wu, M.; Yang, R.; Tan, L.; Zhu, P.; Wei, Q.; Li, J.; Mao, J.; Yoneyama, Y.; et al. Hierarchical zeolite Y supported cobalt bifunctional catalyst for facilely tuning the product distribution of Fischer-Tropsch synthesis. Fuel 2015, 148, 48-57. [CrossRef]

42. Sikarin, T.; Tawan, S.; Lance, L.L.; Siriporn, J. Generation of reductive Zn species over Zn/HZSM-5 catalysts for n-pentane aromatization. Appl. Catal. A. Gen. 2016, 525, 190-196.

43. Xin, M.; Xing, E.; Gao, X.; Wang, Y.; Ying, O.; Xu, G.; Luo, Y.; Shu, X. Ga Substitution during Modification of ZSM-5 and Its Influences on Catalytic Aromatization Performance. Ind. Eng. Chem. Res. 2019, 58, 6970-6981. [CrossRef] 